\title{
The Optimization Design of Double Friction Drawing Reel of Winch Based on ABAQUS
}

\author{
Jiangcheng Wan $^{1}$, a , Ming Jiang ${ }^{1}$, Fei Peng ${ }^{1}$, Nianpeng $\mathrm{Wu}^{1}$ \\ 1 China Electric Power Research Institute, Beijing, 100055 \\ awjc1971@163.com
}

Keywords: Winch; the double friction drawing reel; The parameter design; FEA

\begin{abstract}
In this paper, the research object is the double friction drawing reel of winch which the rated load is $50 \mathrm{kN}$. We identified the main parameters of the double friction drawing reel, includes the bottom diameter of reel , the type of groove, the pitch of groove, the depth of groove, the radius of groove and the number of grooves. We finished the stress analysis between wire ropes and reel, and established 3D model with Solidworks. We finished the finite element analysis of reel and verified the correctness and rationality of the main parameters of reel.
\end{abstract}

\section{Introduction}

The winch is a kind of small traction equipment at the site of no power supply,it is widely used in hoisting tower adjusting the conductor's sag v lifting insulator string and line tackle.Winch is a kind of small traction and lifting equipment which has been used in the construction process commonly.

The reel is the executive body of the winch.It completed traction operations by outputting torque based on the friction between the roll and steel wire ropes.Different roll forms has a great influence on the overall structure of the pulling machine, the steel wire ropes diameter and the working life of it.

The bottom diameter of reel is depending on the diameter of wire rope. When the wire rope's diameter is determinate, the larger the bottom diameter of reel, the smaller the bending stress of the wire rope. Which will help to improve the life of wire ropes. But the larger bottom diameter of reel,which will lead to heavier equipment weight.It is unfavorable for equipment to transport ${ }^{[1]}$.

In summary, we need to study on the stress analysis between reel and wire rope. Then finish the main parameters design of the reel.

\section{Parameters design of the reel}

The bottom diameter.According to requirements for the bottom diameter of reel,which is presented in DL/T 733-2014 《Winch for overhead transmission and transformation project construction ${ }^{[2]}$, the bottom diameter should meet the following requirements:

ds is the diameter of wire rope.

$$
15 d_{\mathrm{s}} \leq D_{\mathrm{s}} \leq 20 \mathrm{~d}_{\mathrm{s}}
$$

The diameter of wire rope.h is $16.5 \mathrm{~mm}$. Substituting it into the equation(1),we can get:

$$
247.5 \leq \mathrm{D}_{\mathrm{s}} \leq 330
$$

After rounding the above results, the size of bottom diameter is $250 \mathrm{~mm}$.

The type of groove. The determination of groove types depending on the contact surface of the groove and wire ropes We should also consider the wire rope will not jump out of groove. In summary, we choose the deep-trough as the type of groove.

The pitch of groove. The pitch of groove is the center distance between two adjacent grooves on the reel. According to requirements of 《Overhead transmission line construction tools manual》 ${ }^{[3]}$, the pitch of groove should meet the following requirements:

$$
\mathrm{t}_{1}=\mathrm{d}_{\mathrm{s}}+(7 \sim 12) \mathrm{mm}
$$

Substituting the diameter of wire rope into equation, we can get: 
The determination of the pitch of groove depending on the compressive stress of the reel during traction process and the weight of the reel.We should also consider the steel wire rope will not jump out of rope groove. In summary, the recommended pitch of groove is $24 \mathrm{~mm}$.

The depth of groove. According to requirements iof 《Overhead transmission line construction tools manual》, the depth of groove should meet the following requirements:

$$
\mathrm{h}_{1}=(0.7 \sim 1) \mathrm{d}_{\mathrm{s}}
$$

Substituting the diameter of wire rope into equation, we can get:

$$
11.55 \leq \mathrm{h}_{1} \leq 16.5
$$

The recommended depth of groove is $12 \mathrm{~mm}$.

The radius of groove. According to requirements of 《Overhead transmission line construction tools manual $》$, the radius of groove should meet the following requirements:

$$
\mathrm{R}_{1}=(0.6 \sim 0.7) \mathrm{d}_{\mathrm{s}}
$$

Substituting the diameter of wire rope into equation, we can get:

$$
9.9 \leq \mathrm{R}_{1} \leq 11.55
$$

The recommended groove depth radius is $10 \mathrm{~mm}$.

The number of grooves. According to requirements of 《Overhead transmission line construction tools manual》, the number of grooves should meet the following requirements

$$
\mathrm{n}=\frac{1}{2 \pi \mu} \ln \frac{\mathrm{P}_{l \max }}{\mathrm{P}_{\mathrm{n}+1}}
$$

$\mu$ is the friction coefficient between the steel wire rope and the reel;

Plmax is the maximum pull force, $N$;

$\mathrm{Pn}+1$ is the tail drag force, in general we use $\mathrm{Pn}+1 \leq 400 \sim 500 \mathrm{~N}$

Because $\mu$ and $\mathrm{Pn}+1$ is empirical parameters, so we use $\mu=0.11 \sim 0.15, \mathrm{Pn}+1=300 \sim 500 \mathrm{~N}$ and Plmax is $50 \mathrm{kN}$.the result are showed in table 1.

Table1 Results of the number of grooves

\begin{tabular}{|c|c|c|}
\hline \multicolumn{1}{|c|}{$\mu$} & 0.11 & 0.15 \\
\hline $300 \mathrm{~N}$ & 7.406 & 5.431 \\
\hline $500 \mathrm{~N}$ & 6.666 & 4.888 \\
\hline
\end{tabular}

Because the tail drag force is an undefined value and it is likely to be less than $300 \mathrm{~N}$,so the recommended number of grooves should great than or equal to 7 .

\section{The force analysis of reel}

The wire rope winding on the drive reel several times, In the process of drawing operation, the wire rope pull conductor by the frictional force generate between the drive and wire rope.

In order to facilitate analysis, we assume that the drive reel is in the stationary state. because of the great resistance on the drive reel.

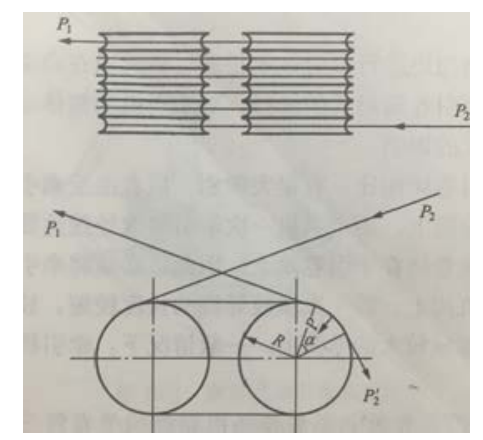

Figure1 The force analysis between wire rope and reel 
Theoretical calculation of pressure on reel by wire rope. When the envelop angle is ${ }^{\alpha}$, the pressure $\mathrm{P}$ on the reel by the wire rope is:

$\mathrm{p}_{1}$ - the traction on the wire rope

$$
\mathrm{p}=\mathrm{p}_{1} \sin \frac{\alpha}{2}+\mathrm{p}_{2}^{\prime} \sin \frac{\alpha}{2}
$$

$\mathrm{p}_{2}^{\prime}$-The pull force produced by friction on the surface of the reel with the small pieces of wire rope at the back of the wire rope.

If we consider the equivalent radius of reel is $\mathrm{R}$, the contact length is $\mathrm{R} \alpha$, we know:

$$
\begin{gathered}
q=\frac{P}{R_{\alpha}}=\frac{\left(p_{1}+p_{2}^{\prime}\right) \sin \frac{\alpha}{2}}{R_{\alpha}} \\
R=\frac{1}{2}\left(D_{s}+d_{s}\right)
\end{gathered}
$$

$\mathrm{q}$ - The pressure produces on the reel by wire rope per unit length.

$\mathrm{D}_{\mathrm{s}}$ - The bottom diameter of reel

$\mathrm{d}_{\mathrm{s}}$ - The diameter of wire rope

When the envelop angle $\alpha$ is very small, the arc length of wire rope is very small, so we can consume the $\mathrm{p}_{1}$ is equal to $\mathrm{p}_{2}^{\prime}$.

$$
\mathrm{q}=\lim _{\alpha \rightarrow 0} \frac{\left(\mathrm{P}_{1}+\mathrm{p}_{2}^{\prime}\right) \sin \frac{\alpha}{2}}{\mathrm{R} \alpha}=\frac{\mathrm{P}_{1}}{\mathrm{R}}
$$

The pressure produces on the reel by wire rope is inversely proportional to the equivalent radius of reel, is proportional to the pull force.

In the formula, we don't have to consider the diameter of wire rope, if we consider the diameter, the $\mathrm{q}$ is:

$$
q=\frac{P_{1}}{L R}
$$

$\mathrm{L}$ - the width of contact area between the wire rope and reel.

The pressure on the rope groove $n$ of reel is:

$$
\mathrm{q}_{\mathrm{n}}=\frac{\mathrm{P}_{\mathrm{n}}}{\mathrm{LR}}
$$

$\mathrm{P}_{\mathrm{n}}$ - the pull fore of wire rope on the rope groove $\mathrm{n}$ of reel.

Table2 The pressure on the rope groove

\begin{tabular}{|c|c|c|c|c|c|c|c|}
\hline $\mathrm{n}$ & $\mathrm{q}_{1}$ & $\mathrm{q}_{2}$ & $\mathrm{q}_{3}$ & $\mathrm{q}_{4}$ & $\mathrm{q}_{5}$ & $\mathrm{q}_{6}$ & $\mathrm{q}_{7}$ \\
\hline Pressure/MPa & 75.05 & 37.61 & 18.85 & 9.45 & 4.73 & 2.37 & 1.19 \\
\hline
\end{tabular}

Theoretical calculation of frictional force on reel by wire rope. We the pressure produce by the wire rope of length $d_{1}$ on the pull force $P_{1}$ is $d_{p}$, then

Because $\mathrm{P}_{1}=\mu \mathrm{p}$

$$
\mathrm{dp}=\mathrm{qdl}=\frac{\mathrm{P}_{1}}{\mathrm{R}} \mathrm{dl}
$$

Because $\mathrm{dl}=\mathrm{Rd} \alpha$, the integral is :

$$
\mathrm{dP}_{1}=\mathrm{d} \mu \mathrm{p}=\mu \frac{\mathrm{P}_{1}}{\mathrm{R}} \mathrm{dl}
$$

The constant $\mathrm{C}$ can be obtained by boundary conditions, when the $\alpha=0, \mathrm{P}_{1}=\mathrm{p}_{2}^{\prime}$ :

$\mathrm{P}_{2}$ - The pull force of wire rope

$$
\begin{gathered}
\ln \frac{\mathrm{P}_{1}}{\mathrm{P}_{2}}=\mu \alpha \\
\mathrm{P}_{2}=\frac{\mathrm{P}_{1}}{\mathrm{e}^{\mu \alpha}}
\end{gathered}
$$

$\mu$-The coefficient of friction between the wire rope and reel。

$\alpha$-the effective envelop angle

The pull force of wire rope on rope groove $n$ of the reel is .

$$
\mathrm{P}_{\mathrm{n}}=\frac{\mathrm{P}_{1}}{\mathrm{e}^{(\mathrm{n}-1) \mu \pi}}
$$

According to the formula , the pull force of wire rope is : 
Table 3 The pull force of wire rope

\begin{tabular}{|c|c|c|}
\hline force & $\mathrm{T}_{1}$ & $\mathrm{~T}_{1}$ \\
\hline 1 & 50000 & 35396.98 \\
\hline 2 & 25058.92 & 17740.2 \\
\hline 3 & 12558.99 & 8891.01 \\
\hline 4 & 6294.29 & 4455.98 \\
\hline 5 & 3154.56 & 2233.24 \\
\hline 6 & 1581 & 1119.25 \\
\hline 7 & 792.36 & 560.94 \\
\hline
\end{tabular}

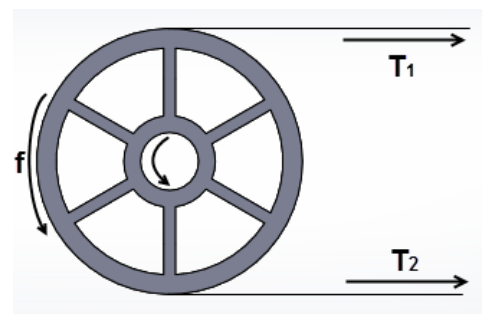

Figure 2The frictional force of groove

As shown is figure, the drive reel rotate the wire rope to pull the conductors, the frictional force between the wire rope and reel is $f$.

$$
\mathrm{T}_{1}=\mathrm{T}_{2}+f
$$

We can obtain the frictional force from the pull force of wire rope. The frictional force as shown in table.

Table 4 The frictional force

\begin{tabular}{|c|c|c|c|c|c|c|c|}
\hline $\mathrm{n}$ & 1 & 2 & 3 & 4 & 5 & 6 & 7 \\
\hline Frictional force/N & 14603 & 7318 & 3667 & 1838 & 921 & 461 & 231 \\
\hline
\end{tabular}

We carry out the finite element analysis to validate the parameters of reel. In order to reduce the number of deformity unit, avoid the error during the mesh of reel, we make some hypothesis ${ }^{[4-5]}$ :

1)Ignore the influence of round corner to the strength and stiffness of reel.

2)In the finite element of reel, we consider the weld as a whole object.

According to the above hypothesis, we establish the three dimensional model with Solidworks, and then lead the simplified model into finite element software. In order to guarantee the accuracy of the model, we must ensure the center of gravity position of finite element model and practical model is identical, the number and attribute of mesh are shown in table 5.

Table 5 The attribute of element

\begin{tabular}{|c|c|c|c|}
\hline quantity & Element types & $\begin{array}{c}\text { Number of abnormal } \\
\text { element }\end{array}$ & $\begin{array}{c}\text { Number of error } \\
\text { element }\end{array}$ \\
\hline 107632 & $\begin{array}{c}\text { C3D8R } \\
\text { (hexahedron element) }\end{array}$ & 0 & 0 \\
\hline
\end{tabular}

Figure 3 The FEM model of reel

In the process of pulling, due to the constraint of assembly position, the reel only can rotate around the axis. In abaqus, we establish the Hinge connection to define the boundary condition. first of all, we establish two reference points on the axis of the corresponding position, establish the coupling connection relationship on reference point 9 with the corresponding area.As shown in figure 4 . 

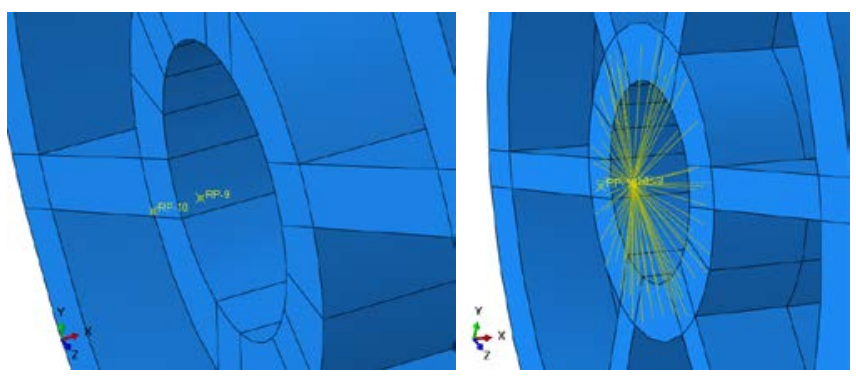

Figure 4 Hinge connection

We establish the Hinge connections between the two reference, and establish the fixed constraint on reference point 10.as shown in figure 5 .

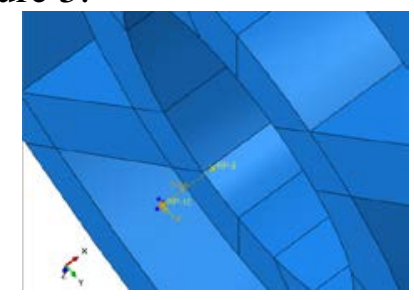

Figure 5 boundary condition

In abaqus, the torque is applied on the point, in order to simulate the torque between the shaft and reel simulate the torque produce by the friction between wire rope and groove of reel, we should establish the coupling relationship between the points and surface ,as shown in figure 6 .

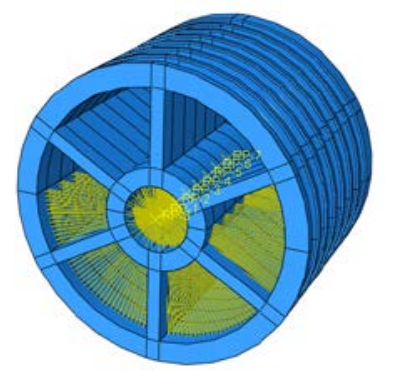

Figure 6 The coupling relationship

After we complete the coupling relationship, we apply the torque of rope groove on the reference PR1-PR7, apply the torque of shaft on reference PR8.

We apply the pressure on the rope groove. As shown in figure 7.

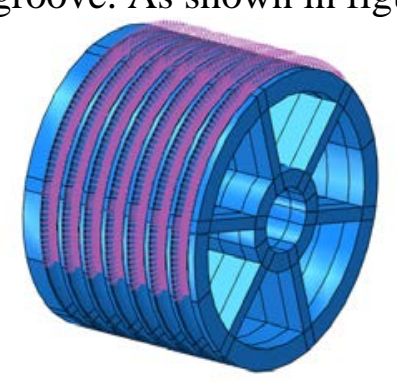

Figure 7 The pressure on the rope groove

After we finish the process of modeling in abaqus, we carry out the static analysis of reel, in order to observe the distribution of stress on the groove of reel. We hidden the stress on the floor of reel, the Von.Mises stress of reel are shown in figure 8. 


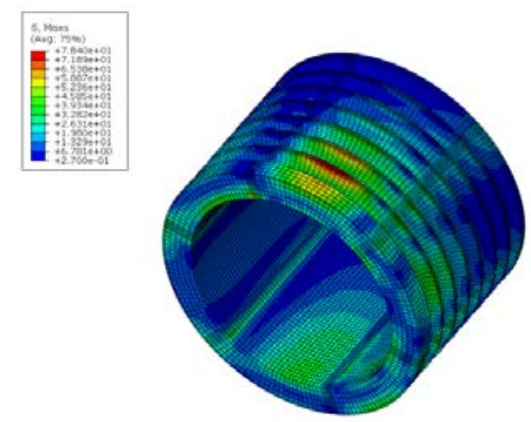

Figure 8The nephogram of stress and displacement

As shown if figure, the maximum stress in the first rope groove and the second rope groove, the value of maximum stress is $78.4 \mathrm{MPa}$.

\section{Conclusion}

In this paper, we designed the structure calculated the parameters of reel, and the made the finite element stress analysis of reel, the conclusions are as follows:

(1)Completed the structure of reel, including the bottom diameter, the shape of groove, the pitch of groove, the depth of groove, the radius of groove round and slot numbers

(2)Completed the theory calculation of pressure produced by wire rope on reel, the maximum value of pressure is $75.1 \mathrm{MPa}$.

(3)Completed the frictional force between the wire rope and groove of reel.The force on seventh slot is $560 \mathrm{~N}$.

(4)Completed the finite element analysis of reel with abaqus, the maximum value of stress is $78.4 \mathrm{MPa}$, the error value is $4 \%$ compared with the value of theoretical calculation.

\section{References}

[1]SONG Ji-ming,HUANG Cheng-yun,ZHU Ke-liang,XU De-zhi.Application of Tractor-Mounted Winches with Overload Protection in UHV Lines Construction.Electric Power Construction[J] ,Vol.29 No.11 Nov.2008.

[2]DL/T 733-2014 《Winch for overhead transmission and transformation project construction》.

[3]JIANG Pin-hai. Overhead transmission line construction tools manual[M].2014

[4]LUO Jian-kang,YIN Bo.Finite element analysis and structural optimization of crane's drum.Machinery Design\&Manafacture[J].No.11,2010.

[5]LI Xin-hua, ZHANG Xiao-ming,CHEN Jin-liang.Stess Analysis of Mine Hoist Drum Based on ANSYS.Coal Mine Machinery[J].Vol 33 No.01,2012. 